\title{
A study on the incidence and severity of hand-foot syndrome in cancer patients treated with capecitabine
}

\author{
Mahanta Neelakshi ${ }^{1}$, Kutum Niharika ${ }^{2}$, Ali AS ${ }^{3}$, Kalita NK $^{4}$, Deka Hitesh ${ }^{5}$, Lokkur PK ${ }^{6}$
}

Received on 12 $2^{\text {th }}$ April 2020; editorial approval on 20 $0^{\text {th }}$ May 2020

\begin{abstract}
Introduction: Hand-Foot Syndrome is a localised dermatologic reaction and is one of the most common adverse effects of capecitabine containing chemotherapy in cancer patients. Although it is not life-threatening toxicity, it can be quite serious, leading to a delay in or discontinuation of anticancer therapy. Objectives: To estimate the incidence of Hand-Foot Syndrome receiving treatment with capecitabine containing chemotherapy at State Cancer Institute and to determine the severity of HandFoot Syndrome. Materials and methods: The study was a hospital-based retrospective study conducted at a State Cancer Institute in Assam, for a period of six months from August 2019 to January 2020. A total of fifty-one cancer patients were included, out of which thirty-three had HandFoot Syndrome. Results: Overall incidence of Hand-Foot Syndrome was $64.7 \%$ cases, $39.4 \%$ of cases in males and $60.6 \%$ cases in females. As per NCI-CTCAE grading, $60.6 \%$ of cases had grade $1 \mathrm{HFS}, 36.4 \%$ of cases had grade 2 and $3 \%$ of cases had grade $3 \mathrm{HFS}$. The first episode of HFS occurred in $12.1 \%$ cases after cycle 1, 60.6\% cases after cycle 2 and $27.3 \%$ cases after cycle 3. Conclusion: The incidence of HFS is common in patients treated with capecitabine and is usually starts within the first two cycles of therapy. It has a significant influence on patients quality of life and abilities.
\end{abstract}

Keywords: NCI-CTCAE; monotherapy; combination therapy.

\section{INTRODUCTION}

Hand-foot syndrome(HFS), which is also known as palmoplantar erythrodysesthesia is a localized dermatologic reaction associated with the initiation of therapy with certain chemotherapeutic agents and is the most frequently reported side effect of oral capecitabine. ${ }^{1}$ Hand-foot syndrome (HFS) has been previously reported as a side effect in $45-56 \%$ of patients treated with capecitabine. ${ }^{2}$

Although the exact pathogenesis of HFS is not clear, it may be due to damaged deep capillaries in the soles of the feet and palms of the hands, leading to a COX inflammatory-type reaction, or related to enzymes involved in the metabolism of capecitabine, namely, thymidine phosphorylase and dihydro pyrimidine dehydrogenase. ${ }^{3}$

The pathological changes which occurred include the vacuolar degeneration of the basal keratinocytes, dermal perivascular lymphocytic infiltration, apoptotic keratinocytes and dermal edema. ${ }^{4}$ The clinical features of HFS are characterized by a prodrome of dysesthesia, painful oedema and erythema of the palms, digits, and soles which may evolve into blisters and erosions. ${ }^{1}$ Although not a lifethreatening toxicity, it can be quite serious, leading to a delay in or discontinuation of anticancer therapy and affecting normal daily activities and the quality of life. If not promptly managed, HFS can progress to an extremely painful and

\footnotetext{
Address of Correspondence:

${ }^{1}$ Associate Professor and HOD

Mobile: +919864016221

Email: neelakshimahanta@gmail.com

${ }^{2}$ Fellow (Corresponding author)

Mobile: +919577324236

Email: niharikakutum66@gmail.com

${ }^{3}$ Senior Resident, ${ }^{4}$ Registrar, ${ }^{5}$ Fellow, ${ }^{6}$ Junior Consultant

Department of Medical Oncology

State Cancer Institute, Gauhati Medical College and Hospital

Bhangagarh-32, Guwahati, Assam, India.
}

Cite this article as: Mahanta Neelakshi, Kutum Niharika, Ali AS, Kalita NK, Deka Hitesh, Lokkur PK. A study on the incidence and severity of hand-foot syndrome in cancer patients treated with capecitabine. Int J Health Res Medico Leg Prae 2020 July;6(2):21-24. DOI 10.31741/ijhrmlp.v6.i2.2020.4 
debilitating condition, causing significant discomfort and impairment of function, potentially leading to worsened quality of life in patients receiving capecitabine. ${ }^{5}$

However, treatment interruption and or dose reduction usually leads to rapid reversal of the signs and symptoms of HFS along with supportive treatments can help alleviate it. ${ }^{6}$ This study aims to estimate the incidence of Hand-Foot Syndrome among cancer patients receiving treatment with capecitabine containing chemotherapy at state cancer institute and to determine the severity of Hand-Foot Syndrome.

\section{METHODS AND MATERIALS}

The study was a hospital-based retrospective study conducted at State Cancer Institute (SCI) in Assam, who attended the Department of Medical Oncology for a period of six months from August 2019 to January 2020. A total of Fifty-one cancer patients were included, who attended for the capecitabine therapy. Out of these fifty-one patients, thirty-three had Handfoot syndrome. The data were collected from the Medical Records Department and patient's records were taken according to criteria as below: Inclusion criteria: 1) Above 18 years age group; 2) Patients who were on treatment with capecitabine containing chemotherapy. Exclusion criteria: 1) Less than 18 years age group; 2) Pregnancy; 3) Lactating mother. We retrieved the data regarding patient's characteristics (age, sex, performance status, the severity of HFS, first episode of HFS from which cycle of chemotherapy, dose adjustment requirement, capecitabine therapy as either monotherapy or combination therapy and chemotherapy settings as either adjuvant or palliative) by reviewing the patient's file from Medical Records Department. Patients who were on capecitabine were assessed clinically/ physically in every cycle receiving capecitabine chemotherapy.

As per NCI CTCAE grading, the severity of Hand-Foot Syndrome was graded who were on capecitabine therapy as shown in Table 1.

Table 1 National cancer institute common terminology criteria for adverse events ${ }^{1}$

\begin{tabular}{|l|l|}
\hline Grade 1 & $\begin{array}{l}\text { Minimal skin changes (erythema, oedema or } \\
\text { hyperkeratosis) without pain. }\end{array}$ \\
\hline Grade 2 & $\begin{array}{l}\text { Skin changes (peeling, blisters, bleeding, oedema } \\
\text { or hyperkeratosis) with pain, limiting instrumental } \\
\text { activities of daily living. }\end{array}$ \\
\hline Grade 3 & $\begin{array}{l}\text { Severe skin changes (peeling, blisters, bleeding, } \\
\text { oedema or hyperkeratosis) with pain, limiting self- } \\
\text { care activities of daily living. }\end{array}$ \\
\hline
\end{tabular}

Performance status is assessed using Eastern Cooperative Oncology Group (ECOG) performance status grading as shown in Table 2.
Table 2 ECOG Performance Status ${ }^{7}$

\begin{tabular}{|l|l|}
\hline Grade 0 & $\begin{array}{l}\text { Fully active, able to carry on all pre-disease } \\
\text { performance without restriction }\end{array}$ \\
\hline Grade 1 & $\begin{array}{l}\text { Restricted in physically strenuous activity, but } \\
\text { ambulatory and able to carry out work of light and } \\
\text { sedentary nature }\end{array}$ \\
\hline Grade 2 & $\begin{array}{l}\text { Ambulatory and capable of all self-care but unable } \\
\text { to carry out any work activities. Up and about more } \\
\text { than 50\% of working hours }\end{array}$ \\
\hline Grade 3 & $\begin{array}{l}\text { Capable of only limited self-care, confined to bed or } \\
\text { chair more than 50\% of working hours }\end{array}$ \\
\hline Grade 4 & $\begin{array}{l}\text { Completely disabled. Cannot carry on any self-care. } \\
\text { Confined to a bed or chair }\end{array}$ \\
\hline Grade 5 & Dead \\
\hline
\end{tabular}

\section{RESULTS}

In this study, out of 33 cases of HFS, 13 were males (39.4\% cases) and 20 were females $(60.6 \%)$ with male-female ratio were $1: 1.5$. As per NCI CTCAE grading, $60.6 \%$ of cases had grade $1 \mathrm{HFS}, 36.4 \%$ of cases had grade $2 \mathrm{HFS}$ and $3 \%$ of cases had grade 3 HFS. The first episode of HFS occurred in $12.10 \%$ cases after cycle $1,60.60 \%$ cases after cycle 2 , $27.30 \%$ cases after cycle 3 and none occurred after cycle 4 . Dose adjustment was done among 33 cases of HFS, of which 12 cases had received $75 \%$ of the total dose, 5 cases had received $50 \%$ of total dose and other 2 cases were discontinued. Capecitabine induced HFS to include primary diseases like CA stomach, CA colon, CA breast, CA rectum etc. About 19 cases (57.60\%) received capecitabine as monotherapy and 14 cases $(42.4 \%)$ as combination therapy. Some 12 cases (36.4\%) was on adjuvant setting and 21 cases $(63.6 \%)$ were on the palliative setting.

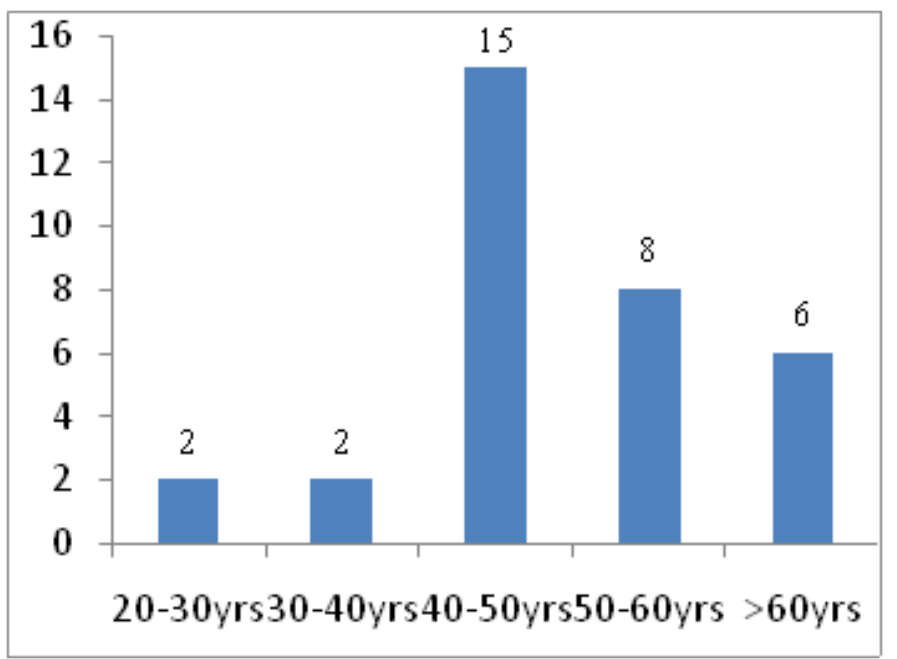

Figure 1 Age distribution

Among 33 HFS patients, 2 cases were in 20-30 yrs age group, 2 cases were in 30-40 yrs age group, 15 cases were in 40-50 yrs age group, 8 cases were in 50-60 yrs age group and 6 cases were in $>60$ yrs age group. 


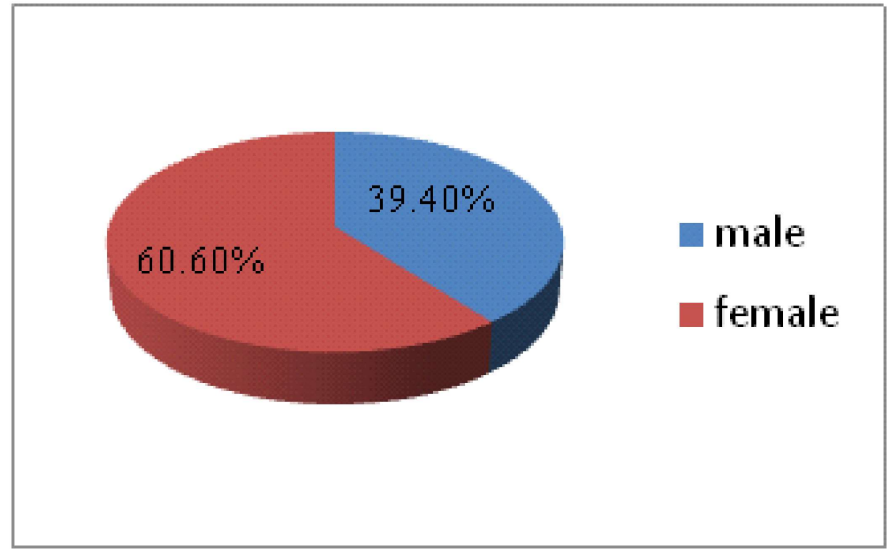

Figure 2 Gender distribution

Out of 33 HFS patients, 13 cases were males (39.4\% cases) and 20 cases were females $(60.6 \%)$ with male-female ratio was $1: 1.5$.

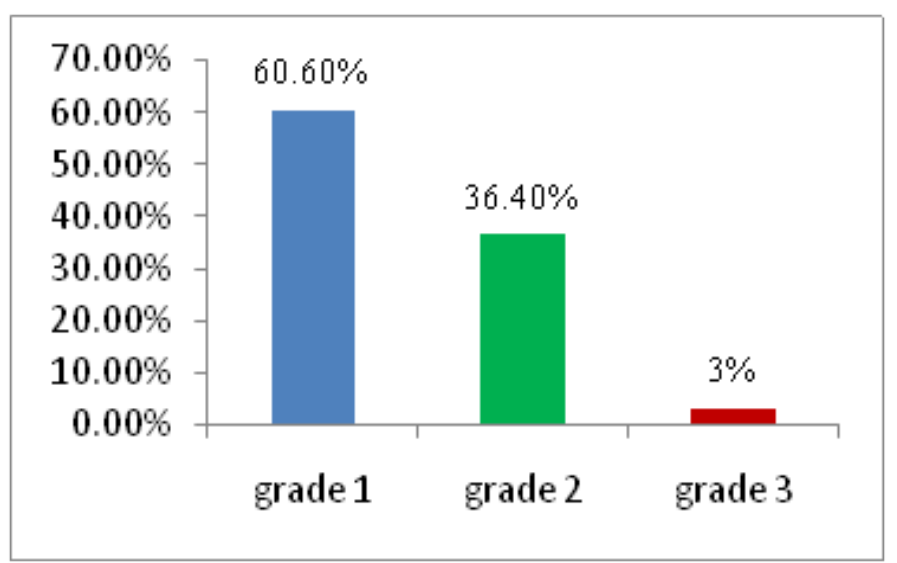

Figure 3 Severity of HFS

As per NCI CTCAE grading, $60.60 \%$ of cases had grade 1 HFS, $36.40 \%$ of cases had grade 2 HFS and $3 \%$ of cases had grade 3 HFS.

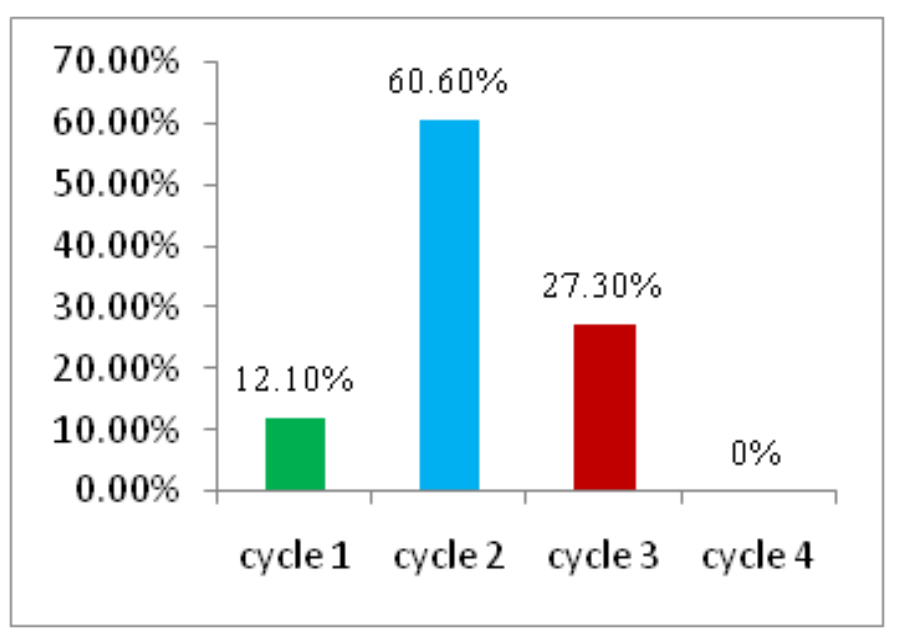

Figure 4 First episode of HFS

The first episode of HFS occurred in $12.10 \%$ cases after cycle $1,60.60 \%$ cases after cycle $2,27.30 \%$ cases after cycle 3 and none occurred after cycle 4 .

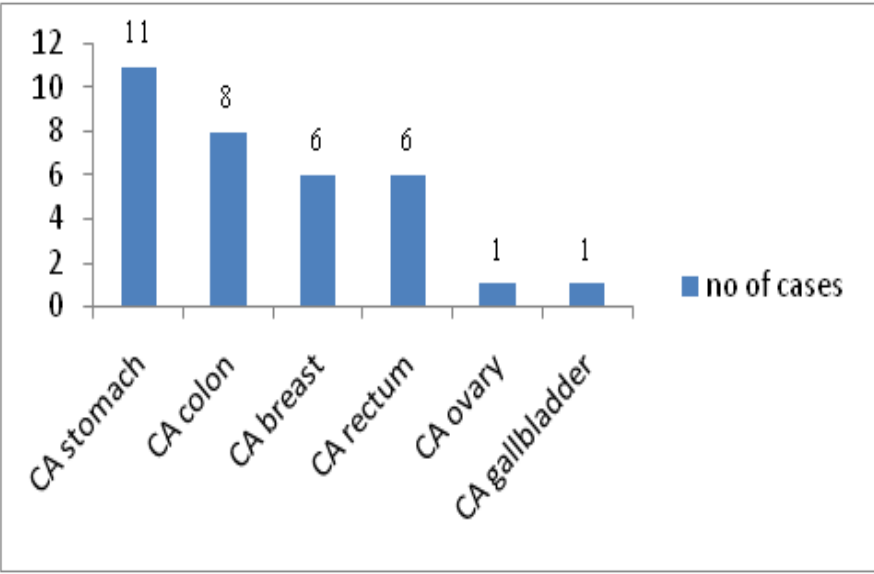

Figure 5 Primary diseases

Patients those who were on Capecitabine induced HFS includes primary diseases like CA stomach (11 cases), CA colon (8 cases), CA breast (6 cases), CA rectum (6 cases), CA Ovary (1 case) and CA Gall bladder ( 1 case).

\section{DISCUSSION}

In this study, the overall incidence of HFS was found to be $64.7 \%$, with a slight predominance among females with malefemale ratio was 1:1.5 (13 males and 20 females).

In this study, $60.6 \%$ of cases experienced grade 1 HFS. A study done by Matsuoka Hiroshi et al had $66.7 \%$ cases of grade $1 \mathrm{HFS}, 10 \%$ cases of grade 2 and none had grade 3 HFS. ${ }^{8}$ The Study of Azuma Yuichiro et al showed $37.8 \%$ cases of grade $1 \mathrm{HFS}, 31.6 \%$ cases of grade 2 and $3.1 \%$ cases of grade $3 .{ }^{9}$ A Study done by Yap Yoon Sim et al found $28.6 \%$ of grade $1 \mathrm{HFS}, 31.42 \%$ of grade 2 and $2.9 \%$ of grade 3 HFS. ${ }^{6}$ Son Hyun Sook et al study showed that $50.7 \%$ had grade 1, $33.8 \%$ had grade 2 and $15.5 \%$ had grade $3 .{ }^{10}$

Among the 33 patients who had HFS, 20 patients $(60.6 \%)$ had their first episode after cycle 2. The Study done by Son Hyun Sook et al showed that $26.1 \%$ had the first episode of HFS after cycle 1 and $73.9 \%$ had after cycle $2 .{ }^{9}$

In this study, 12 cases $(36.4 \%)$ of HFS was on adjuvant setting and 21 cases $(63.6 \%)$ of HFS was on the palliative setting. A Study done by Yap Yoon Sim et al found that those who had HFS had $21 \%$ cases were on adjuvant and $79 \%$ cases were on palliative. ${ }^{6}$

In the present study, about $19(57.60 \%)$ cases, received capecitabine as monotherapy and $14(42.4 \%)$ cases as combination therapy. A study done by Muller Volkmaret al showed that those who had HFS received capecitabine as monotherapy in $38.8 \%$ cases and $61.2 \%$ cases received as combination therapy. ${ }^{11}$

\section{CONCLUSION}

The incidence of HFS is common in patients treated with capecitabine and is usually starts within the first two cycles of therapy. Although the incidence of a severe grade of HFS is low, it can have a significant influence on patient's quality of life and abilities. Prevention, early recognition, and 
implementation of various management strategies for HFS are important in optimizing patient's quality of life and minimizing unfavourable outcomes. The study comprises of relatively a small sample size for a short period. Hence, a larger prospective study with a large sample size for long duration is required to arrive at a definite conclusion. Whether the results of the present study can be reproduced in other multicentre studies has yet to be determined. Further studies are therefore necessary.

Limitations: Varying doses of capecitabine used in this study and relatively small sample size and short duration of the study.

Acknowledgements: A sincere thanks to all the patients included in the study and all the health staff workers of state cancer institute GMC, for their great support.

Conflict of interest: None declared.

Source of funding: None declared.

Ethical clearance: Taken.

Author Contributions: Conception/design: Dr Niharika Kutum, Dr Neelakshi Mahanta, Dr Naba K Kalita; Provision of study material or patients: Dr Niharika Kutum, Dr Neelakshi Mahanta, Dr Naba K Kalita, Dr Hitesh Deka, Dr Pooja Lokkur, Dr Alfarid S Ali; Collection and/or assembly of data: Dr Niharika Kutum, Dr Alfarid S Ali, Dr Hitesh Deka, Dr Pooja Lookur; Data analysis and interpretation: Dr Niharika Kutum, Dr Naba K. Kalita, Dr Neelakshi Mahanta; Manuscript writing: Dr Niharika Kutum Final approval of Manuscript by all the authors.

\section{REFERENCES}

1. Hoesly FJ, Baker SG, Gunawardane ND, Cotliar JA. Capecitabine-induced hand-foot syndrome complicated by pseudomonal super infection resulting in bacterial sepsis and death: case report and review of the literature. Arch Dermatol 2011;147(12):1418-23.

2. Abushullaih S, Saad ED, Munsell M, Hoff PM. Incidence and severity of hand-foot syndrome in colorectal cancer patients treated with capecitabine: a single-institution experience. Cancer Invest 2002;20(1):3-10.

3. Saif MW. Capecitabine and hand-foot syndrome,
Expert Opinion on Drug Safety 2011;10(2):159-69.

4. Lee SD, Kim HJ, Hwang SJ, Kim YJ, Nam SH, Kim BS. Hand-foot syndrome with scleroderma-like change induced by the oral capecitabine: a case report. Korean J Intern Med 2007;22(2):109-12.

5. Kang YK, LeeSS, Yoon DH, LeeSY, YoungJC, Kim $\mathrm{MS}$, et al. Pyridoxine is not effective to prevent handfoot syndrome associated with capecitabine therapy: results of a randomized, double-blind, placebocontrolled study. J of clinical oncology 2010;28(24):3824-9.

6. Yap YS, Kwok LL, Syn N. Predictors of hand-foot syndrome and pyridoxine for prevention of capecitabine-induced hand-foot syndrome: a randomized clinical trial. JAMA Oncol 2017;3(11):1538-45.

7. Oken MM, Creech RH, Tormey DC, et al. Toxicity and response criteria of the Eastern Cooperative Oncology Group. Am J Clin Oncol 1982;5(6):649-55

8. Hiroshi Matsuoka, Yoko Katagata, Hideki Ohta, Koutarou Maeda. Multidisciplinary approach to the management of capecitabine associated hand foot syndrome in cancer patients receiving capecitabine plus oxaliplatin and bevacizumab for advanced colorectal cancer. Fujita Medical Journal 2017;3(1):1-5.

9. Yuichiro Azuma, Kojiro Hata, Kimie Sai, Ryoko Udagawa. Significant association between hand-foot syndrome and efficacy of capecitabine in patients with metastatic breast cancer. Biological and pharmaceutical bulletin June 2012;35(5):717-24.

10. Son HS, Lee WY, Lee WS, Yun SH, Chun HK. Compliance and effective management of the handfoot syndrome in colon cancer patients receiving capecitabine as adjuvant chemotherapy. Yonsei Med J 2009;50(6):796-802.

11. Muller V, Fuxius S, Steffens CC, Lerchenmüller C, Luhn B. Quality of life under capecitabine (Xeloda $\left.{ }^{\circledR}\right)$ in patients with metastatic breast cancer: data from a german non-interventional surveillance study. Oncology research and treatment 2014;37(12):748-55. 